\title{
Study of serum levels and skin expression of S100B protein in psoriasis*
}

\author{
Samar Abdallah M. Salem ${ }^{1}$ \\ Mervat Harvy ${ }^{2}$ \\ Wafaa Abdelaal ${ }^{4}$ \\ Omneya Osama El- Hagry ${ }^{3}$ \\ DOI: http:/ / dx.doi.org/10.1590/abd1806-4841.20175038
}

\author{
Ekramy Ahmed El-Khateeb ${ }^{1}$ \\ Hanaa Mohamed El-Sayed Emam ${ }^{3}$ \\ Reham El Nemr ${ }^{4}$
}

\begin{abstract}
BACKGROUND: S100B protein was reported to be elevated in psoriatic patients' serum, with no previous evaluation of its skin expression, in contrast to the extensively studied S100 protein.

Овлестіvе: To evaluate the serum level and skin expression of S100B in psoriasis to assess its possible involvement in its pathogenesis.

Methods: Serum level of S100B protein was estimated in 40 psoriatic patients of different clinical varieties and 10 healthy controls. S100B protein expression was assessed immunohistochemically in lesional and non-lesional skin of patients and in normal skin of controls. Relation to disease severity was also evaluated.

RESULTS: Serum level of S100B protein was significantly higher in psoriatic patients $(0.15 \pm 0.03 \mu \mathrm{g} / 1)$ than in controls $(0.03 \pm 0.007$ $\mu \mathrm{g} / \mathrm{l})$ (P-value $<0.001$ ) with no significant correlation with PASI score. On comparing grades of S100B protein skin expression in lesional and non-lesional skin biopsies, a statistically significant difference was found $(\mathrm{P}=0.046)$ with higher percentage of strong S100B skin expression (60\%) in non-lesional than in lesional (42\%) skin. All the control biopsies showed negative expression. STUDY LIMITATIONS: Relatively small sample size with a limited range of low PASI scores.

CONCLUSION: This study points to a potential link between psoriasis and S100B protein with higher serum and skin expression in patients than in controls.
\end{abstract}

Keywords: Immunohistochemistry; Psoriasis; S100 Proteins

\section{INTRODUCTION}

Psoriasis is a chronic relapsing skin condition affecting the population worldwide. ${ }^{1}$ Its etiology includes genetic and environmental factors. ${ }^{2}$ It is a T-cell mediated autoimmune disorder. Despite the significant advances in understanding the pathogenesis of psoriasis, its exact etiology remains unknown. ${ }^{1}$ Numerous immunologic, bioregulatory and biochemical changes accompanying this disease were described. ${ }^{3}$

The S100 family of proteins is acidic calcium and zinc binding low molecular weight proteins mainly present in astrocytes and in a population of oligodendrocytes of the central nervous system. ${ }^{4}$ They are found exclusively in vertebrates, with at least 25 members found in human. ${ }^{5}$

S100 proteins are thought to have intracellular and extracellular roles in the regulation of many diverse processes such as protein phosphorylation, cell growth and motility, cell-cycle regulation, transcription, differentiation, $\mathrm{Ca}^{2+}$ homeostasis and cell survival by serving as calcium sensor proteins that, upon activation, regulate the function and/or subcellular distribution of specific target proteins. ${ }^{5,6}$ They play a role in the pathogenesis of epidermal diseases, as selected S100 proteins are markedly overexpressed in psoriasis, wound healing, skin cancer, inflammation, cellular stress, and other epidermal states. ${ }^{7}$

S100B protein is normally present in the epidermis in Langerhans' cells and melanocytes and in the dermis in Schwann cells, sensory corpuscles, and sweat glands. On the other hand, it is abnormally expressed in melanocytic lesions as nevi, melanoma and melanoma metastases. ${ }^{8}$ In general, it is expressed in dendritic cells and cells of neurogenic origin. Increased circulating S100B levels have been also demonstrated in gastrointestinal cancer, neurological diseases, cerebrovascular or cardiovascular ischemic disease, and cardiac arrest. ${ }^{9}$

A previous study showed an elevation of S100B protein level in the sera of psoriatic patients, which was directly correlated with the severity of psoriasis by PASI score. ${ }^{10}$ Considering this, to-

Received on 12.08.2015.

Approved by the Advisory Board and accepted for publication on 15.05.2016.

* Study performed at Dermatology \& Venereology Department, Faculty of Medicine, Ain Shams University, Cairo, Egypt and National Research Center - Giza, Egypt. Financial support: None

Conflict of interest: None.

Department of Dermatology and Venereology, Ain Shams University - Cairo, Egypt.

Department of Medical Biochemistry, National Research Center - Giza, Egypt.

Department of Dermatology and Venereology, National Research Center - Giza, Egypt.

Department of Pathology, National Research Center - Giza, Egypt. 
gether with absence of previous reports on this protein expression in psoriatic skin, the aim of this study was to evaluate S100B serum level and skin expression in psoriasis to assess its possible involvement in the disease pathogenesis.

\section{METHODS}

\section{Subjects}

This study included 50 subjects divided into two groups. Group I: 40 psoriatic patients of different clinical varieties (guttate, flexural, erythrodermic and plaque psoriasis). They were eight women and 32 men, aged from 8 to 67 years. Group II: 10 healthy volunteers as control. They were three women and seven men, aged from 18 to 50 years. Subjects were recruited from the outpatient dermatology clinics of Ain Shams University Hospitals, Cairo, Egypt; and National Research Center, Giza, Egypt. All subjects gave informed consent to participate in this study. The study was approved by the National Research Centre ethical committee.

Exclusion criteria included patients with malignancy, cerebrovascular or cardiovascular ischemic disease, heart surgery or brain trauma within the last year, cerebral dysfunction or retardation, peripheral nervous system injury, and renal insufficiency.

\section{Methods}

All subjects were subjected to detailed history taking, complete general and dermatological examination, evaluation of psoriasis severity in patients by Psoriasis Area and Severity Index (PASI) score, and assessment of S100B protein level in serum by ELISA and in tissue by immunohistochemistry. ${ }^{11}$

Measurement of S100B protein in human serum

Patients had $5 \mathrm{ml}$ of blood collected by venipuncture. Samples were centrifuged within one hour after blood collection for 10 minutes. Specimens were capped and kept frozen at $-20^{\circ} \mathrm{C}$ until assay by ELISA using mouse monoclonal anti-S100B antibodies (DiaSorin Stillwater, Minnesota 55082-0285, U.S.A).

Biopsies

Analysis took $5 \mathrm{~mm}$ punch biopsies from psoriatic and non-psoriatic skin of patients as well as from normal skin of control group. Biopsies were fixed in 10\% neutral buffered formalin and paraffin embedded sections were prepared. They were stained by hematoxylin and eosin stain and examined by light microscopy to confirm the diagnosis; and by immunohistochemical staining using monoclonal antibody against $\mathrm{S100B}$ protein by immunoperoxidase technique.

Immunohistochemical staining

Deparaffinization, rehydration, and antigen retrieval were conducted followed by peroxidase and protein block. The sections were treated with $10 \%$ normal horse serum for $20 \mathrm{~min}$. The primary antibody employed was the mouse monoclonal anti-S100B antibody "S-100 $\beta$ chain (SB6): sc-58841" (Santa Cruz Biotechnology, Inc., CA, U.S.A). Detection was conducted using an Ultravision detection system (DAKO, Denmark). Diaminobenzidine was used as chromogen and counterstaining was performed with Mayer's hematoxylin. Negative controls were prepared by omitting the primary antibodies. Sections from melanoma were used as a positive control for S100B. Positive cytoplasmic staining was demonstrated. ${ }^{8}$

Scoring of the immunostained sections

Immunostaining were evaluated blindly regarding the pa- tients and the controls. The immunoreactivity for S100 is mainly cytoplasmic (the hair bulbs and sweat glands ducts were used as internal positive control). Staining intensities were analyzed microscopically and divided according to Park and Min (2003) into: no staining $(-)$, weak $(+)$ and strong $(++) .{ }^{12}$

\section{Statistical analysis}

Statistical calculations were performed using computer programs SPSS (Statistical Package for the Social Science; SPSS Inc., Chicago, IL, USA) version 15 for Microsoft Windows. Data was statistically described in terms of range, mean \pm standard deviation $( \pm \mathrm{SD})$ or median (interquartile range $[\mathrm{IQR}]$ ), frequencies and percentages, when appropriate. Comparison of numerical variables between the study groups was conducted using Student $t$ test for independent samples in comparing two groups when normally distributed and Mann Whitney U test for independent samples when not normally distributed. Comparison of normally distributed numerical variables between more than two groups was performed using one way analysis of variance (ANOVA) test with post- hoc multiple 2-group comparisons. Non-normal numerical variables between more than two groups were compared using Kruskal Wallis test with post-hoc multiple 2-group comparisons. After ANOVA, Bonferroni post-hoc test was used and after Kruskal Wallis test, multiple Mann Whitney tests with Bonferroni adjustment for multiple comparisons were used. For comparing categorical data, Chi square (c2) test was performed with adjusted standardized residual analysis. Regarding the adjusted residuals, any value $>1.96$ or $<-1.96$ was considered statistically significant. Exact test was used when the expected frequency was less than 5. Correlation between various variables was performed using Pearson correlation coefficient and Spearman rank correlation for parametric and non-parametric variables, respectively. P value $<0.05$ was considered statistically significant.

\section{RESULTS}

This study included 40 psoriatic patients of different clinical varieties. They were eight women $(20 \%)$ and $32(80 \%)$ men, with mean age $38.95 \pm 14.651$ years. The controls were three women $(30 \%)$ and seven men $(70 \%)$, with mean age $31.3 \pm 11.40$ years. No statistically significant difference was detected between patients and controls regarding age $(\mathrm{P}$-value $=0.087)$ and sex $(\mathrm{P}$-value $=0.495)$.

Patients were divided into four subgroups according to the type of psoriasis; 14 (35\%) plaque-type, 7 (17.5\%) erythrodermic, 8 (20\%) flexural and $11(27.5 \%)$ guttate psoriatic patients. Mean age at disease onset was $31.07 \pm 13.54$ years, median (IQR) of disease duration was 3.00 (3.00-10.00) years, and median (IQR) of PASI score was 7.700 (7.700-11.900). Comparing the means of age in different psoriasis subtypes and controls; and the duration of the disease, age at disease onset and PASI score in different clinical variants of psoriasis showed no statistically significant difference $(\mathrm{P}$-values $=0.221$, $0.057,0.774,0.700$ respectively).

Mean S100B serum level was significantly higher in psoriatic patients $(0.15 \pm 0.03 \mu \mathrm{g} / \mathrm{l})$ than in controls $(0.03 \pm 0.007 \mu \mathrm{g} / \mathrm{l})$ (P-value $<0.001)$. No statistically significant correlation was detected between serum level of S100B protein and variables including age $(r=0.145$, P-value $=0.378)$, age at disease onset $(r=0.017, P$-val$\mathrm{ue}=0.920)$, duration of the disease $(\mathrm{rs}=-0.077, \mathrm{P}$-value $=0.641)$ and 
PASI score ( $\mathrm{rs}=0.061, \mathrm{P}$-value=0.711). Mean serum level of S100B protein was found to be significantly higher in male $(0.15 \pm 0.03 \mu \mathrm{g} / \mathrm{l})$ than female patients $(0.13 \pm 0.02 \mu \mathrm{g} / \mathrm{l})(\mathrm{P}$-value $=0.038)$.

Comparing the mean serum levels of $\mathrm{S} 100 \mathrm{~B}$ protein in different clinical variants of psoriatic patients and controls, a statistically significant difference was detected (P-value $<0.001$ ). On comparing each clinical variant of psoriatic patients with control, a statistically significant difference was detected with higher serum S100B protein in disease groups. Comparing each two variants of psoriasis regarding mean serum level of S100B protein, no statistically significant difference was detected (Table 1).

Comparison of the frequency of positive S100B skin expression in lesional skin (26 cases [65\%]) and non-lesional skin (26 cases [65\%]) showed no statistically significant difference (P-value=1.000).

Comparing grades of S100B protein skin expression in lesional and non-lesional skin biopsies, a statistically significant difference was found (P-value=0.046). The percentage of those with strong S100B skin expression was higher in non-lesional $(60 \%)$ compared with lesional (42.5\%) biopsies. However, regarding weak expression, the percentage was $5 \%$ and $22.5 \%$, respectively (Table 2). All the control biopsies showed negative expression (Figure 1).

In non-lesional skin, plaque-type psoriasis scored the highest frequency of positive skin expression of S100B protein $(34.6 \%)$ followed by flexural and guttate psoriasis ( $23 \%$ each) and erythrodermic psoriasis (19.2\%). In lesional skin biopsies, plaque-type psoriasis also scored highest rate of positive skin expression of S100B protein $(34.6 \%)$, followed by guttate $(30.8 \%)$, flexural $(23 \%)$, and erythrodermic psoriasis (11.5\%).
Comparing the frequency of positive skin expression of S100B protein in lesional and non-lesional skin biopsies between different psoriasis variants ( $\mathrm{P}$-value $=0.799$ and 0.541 respectively) and between men and women ( $\mathrm{P}$-value $=0.868$ in both) showed no statistically significant difference.

No statistically significant difference was detected when comparing grades of S100B protein skin expression of lesional and non-lesional skin in men ( $\mathrm{P}$-value $=0.186)$ and in women $(\mathrm{P}$-value $=0.092)$.

Comparison between men and women regarding the grades of S100B skin expression in lesional skin showed no statistically significant difference (P-value $=0.419)$; whereas in non lesional skin, it showed a statistically significant difference with higher percentage of strong expression in men $(65.6 \%)$ than in women $(37.5 \%)$ and lower percentage of weak expression in the formers than the latters ( $0 \%$ and $25 \%$ respectively, which was the cause of the significant difference) $(\mathrm{P}$-value $=0.012)$.

TABLE 2: Comparison between grades of S100B expression among psoriasis patients in lesional and non-lesional skin biopsies

\begin{tabular}{|c|c|c|c|c|}
\hline \multicolumn{5}{|c|}{$\begin{array}{c}\text { TABLE 2: Comparison between grades of S100B } \\
\text { expression among psoriasis patients in lesional and } \\
\text { non-lesional skin biopsies }\end{array}$} \\
\hline & \multicolumn{3}{|c|}{ Psoriasis cases N (\%) } & \multirow{2}{*}{$\begin{array}{l}\text { P-value/ } \\
\text { significance }\end{array}$} \\
\hline & Non-lesional & Lesional & Total & \\
\hline $\begin{array}{l}\text { Negative } \\
\text { expression }\end{array}$ & $14(35)$ & $14(35)$ & $28(35)$ & \multirow{4}{*}{$0.046 / S$} \\
\hline $\begin{array}{l}\text { Weak } \\
\text { expression }\end{array}$ & $2(5)$ & $9(22.5)$ & $11(13.75)$ & \\
\hline $\begin{array}{l}\text { Strong } \\
\text { expression }\end{array}$ & $24(60)$ & $17(42.5)$ & $41(51.25)$ & \\
\hline Total & $40(100)$ & $40(100)$ & $80(100)$ & \\
\hline
\end{tabular}

S: significant

TABLE 1: Comparison between mean serum levels of S100B protein among psoriatic patients with different clinical variants

\begin{tabular}{llllllll} 
& $\begin{array}{l}\text { Plaque-type } \\
\text { N=14 }\end{array}$ & $\begin{array}{l}\text { Erythrodermic } \\
\mathbf{N = 7}\end{array}$ & $\begin{array}{l}\text { Flexural } \\
\mathbf{N}=\mathbf{8}\end{array}$ & $\begin{array}{l}\text { Guttate } \\
\mathbf{N = 1 1}\end{array}$ & $\begin{array}{l}\text { Total } \\
\mathbf{N}=\mathbf{4 0}\end{array}$ & $\begin{array}{l}\text { Control } \\
\mathbf{N}=\mathbf{1 0}\end{array}$ \\
\hline $\begin{array}{l}\text { Serum level } \\
\text { of S100B }(\mu \mathrm{g} / \mathrm{l})\end{array}$ & $0.15 \pm 0.03$ & $0.15 \pm 0.04$ & $0.13 \pm 0.03$ & $0.16 \pm 0.03$ & $0.13 \pm 0.06$ & $0.031 \pm 0.01$ & $<0.001^{*}$ \\
\hline
\end{tabular}

Control vs. erythrodermic: $\mathrm{P}<0.001^{*}$, Control vs. flexural: $\mathrm{P}<0.001^{*}$, Control vs. guttate: $\mathrm{P}<0.001^{*}$, Control vs. plaque-type: $\mathrm{P}<0.001^{*}$, Plaque-type vs. erythrodermic: NS (P=1.000), Plaquetype vs. flexural: NS ( $\mathrm{P}=0.092)$, Plaque-type vs. guttate: NS ( $\mathrm{P}=0.455)$, Erythrodermic vs. flexural: NS ( $\mathrm{P}=0.129)$, Erythrodermic vs. guttate: NS ( $\mathrm{P}=0.522)$, Flexural vs. guttate: NS ( $\mathrm{P}=0.073)$. NS: non significant, *: significant
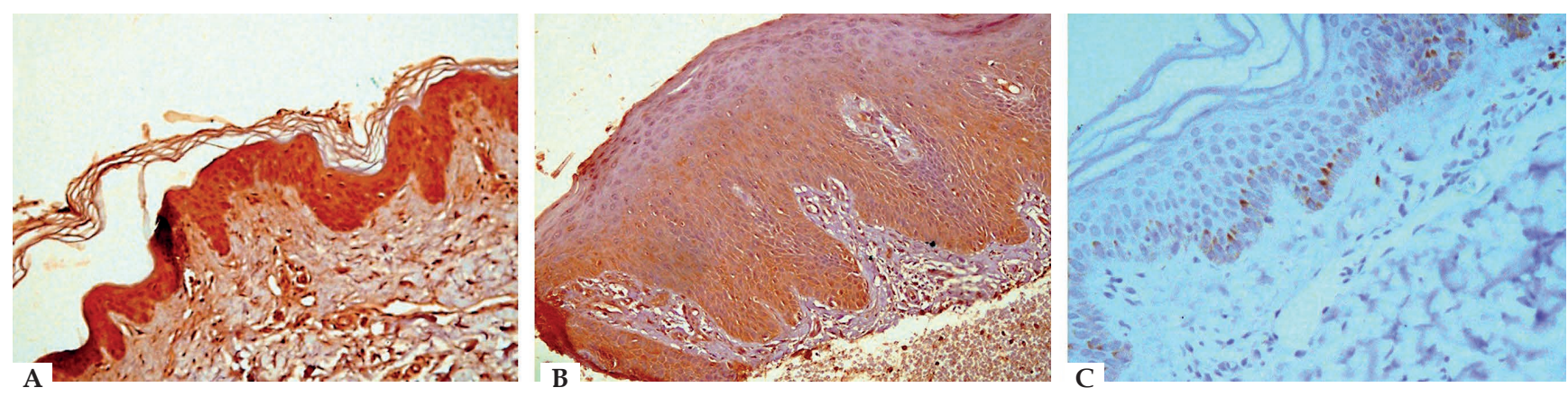

FIGURE 1: A. Non-lesional skin of psoriasis patient showing strong cytoplasmic positivity (+2 grade) for S100B in the epidermis (S100B IHC staining, $\times 400)$. B. Lesional psoriatic skin showing epidermal acanthosis with regular elongation of the rete ridges, and marked hyperkeratosis with weak cytoplasmic positivity (+1 grade) for S100B in the epidermis (S100B IHC staining, $\times 400)$. C. Normal skin of control showing negative staining for S100B in the epidermis with few scattered S100B positive basal and suprabasal layers and melanocytes (S100B IHC staining, $\times 400$ ) 
Comparison between different clinical psoriasis variants regarding lesional and non-lesional S100B skin expression showed no statistically significant difference ( $P$-value $=0.541$ and 0.799 respectively).

Comparing serum level of S100B protein in relation to skin expression revealed that serum S100B protein was significantly higher among patients graded as weak and strong S100B expression in lesional skin compared to those with negative expression. This serum level showed no significant difference in different grades of expression in non-lesional skin (Table 3).

No statistically significant correlation was detected between the mean serum S100B protein level and S100B skin expression grade in lesional ( $\mathrm{rs}=0.03, \mathrm{P}=0.854$ ) and non-lesional ( $\mathrm{rs}=-0.039$, $\mathrm{P}$-value $=0.815$ ) skin biopsies.

\section{DISCUSSION}

Paradisi et al. (2007) observed an elevation in S100B protein level in the sera of psoriatic patients, which was directly correlated with the severity of psoriasis. ${ }^{10}$ Donato et al. (2009) noticed multiple potential cross-points between psoriasis and serum S100B protein such as their close relation with specific cutaneous cells as monocytes/macrophages, lymphocytes and neutrophils. ${ }^{13}$ Scaccianoce et al. (2004) added stress to these cross-points between psoriasis and S100B. ${ }^{14}$

Therefore, the current research was conducted to explore this potential relation. Investigation of serum level of S100B as well as its skin expression in lesional and non-lesional skin in comparison to age- and sex-matched controls was performed.

In comparison to control, significant elevation in serum S100B level in psoriatic patients as a whole and within each group of clinical variants was detected; the finding that might be explained in the context that S100 proteins concentrations measured in body fluids may be due to their release from damaged cells as well as their secretion under pathological conditions. ${ }^{15}$ However, our present study failed to confirm the significant correlation with psoriasis severity reported by Paradisi et al. in 2007. ${ }^{10}$

The significantly higher skin expression of S100B in psoriatic skin than controls was expected based on the well-known role of dendritic cells in the pathogenesis of psoriasis. ${ }^{16}$ Comparing S100B protein skin expression grades in lesional and non lesional skin, a statistically significant difference was found with higher percentage of strong S100B skin expression in non lesional than in lesional biopsies. Interestingly, the number of patients' biopsies with positive S100B expression was found to be equal in lesional and non-lesional

\section{TABLE 3: Comparison between serum level of S100B} protein in relation to skin expression

\begin{tabular}{llll}
\multicolumn{2}{l}{$\begin{array}{l}\text { Skin expression of S100B } \\
\text { protein }\end{array}$} & $\begin{array}{l}\text { Serum level } \\
\text { of S100B }(\mu \mathrm{g} / \mathrm{l})\end{array}$ & $\begin{array}{l}\text { P-value/ } \\
\text { significance }\end{array}$ \\
\hline Lesional & Negative $(\mathrm{n}=14)$ & $0.096 \pm 0.06$ & $0.04 / \mathrm{S}$ \\
& Weak $(\mathrm{n}=9)$ & $0.16 \pm 0.03$ & \\
& Strong $(\mathrm{n}=17)$ & $0.15 \pm 0.03$ & \\
Non-lesional & Negative $(\mathrm{n}=14)$ & $0.1 \pm 0.07$ & $0.08 / \mathrm{NS}$ \\
& Weak $(\mathrm{n}=2)$ & $0.11 \pm 0.01$ & \\
& Strong $(\mathrm{n}=24)$ & $0.15 \pm 0.03$ &
\end{tabular}

NS: non significant, S: significant skin. However, the grade of positivity was significantly lower in lesional skin, which may be explained by the possible overwhelming of psoriatic epidermis, whether lesional or non lesional, by Langerhans' cells which gave the significant positivity for S100B and on eruption of the disease; the migration of Langerhans' cells to the regional lymph nodes as a response to IL- $1 \beta$ and TNF- $\alpha$, as reported by Cumberbatch et al. in 2006, may consequently decrease the epidermal expression of S100B. ${ }^{17}$ The presence of significantly higher grade of $\mathrm{S100B}$ expression in non-lesional skin denotes that psoriasis is a systemic disease and not a disease of lesional skin only. To the best of our knowledge, study of skin expression of S100B protein in psoriasis was not previously reported in literature.

The lack of significant differences between clinical variants as regards grades of S100B skin expression implies that psoriasis/ S100B potential link may be related to the common pathway of psoriasis pathogenesis rather than the wide range of its clinical end forms.

Other hypotheses were introduced in the same context. Eckert et al. reported, in 2004, that S100 proteins may be exported from the cell and function as chemokines. ${ }^{7}$ S100B might also leak from damaged cells thereby accumulating in the extracellular space and entering the blood stream, which may also offer an explanation of its significant decline in lesional skin. ${ }^{13,18}$

The absence of a significant correlation between serum S100B and PASI score within this study stands against the "leakage" hypothesis mentioned above. However, Paradisi et al., in 2007, supported it with a significant correlation of S100B with the disease severity. ${ }^{10}$ Our finding as regards this correlation may not be so accurate being based on a relatively small sample size with a limited range of low PASI scores. Future studies with larger sample size and wider range of different severity grades may be needed to clarify this issue.

Comparison of serum S100B levels among psoriatic men and women revealed a statistically significant higher level in men; the same finding also was found on comparing grades of S100B skin expression among men and female in non lesional skin biopsies. Our finding may be due to the larger number of men than women included in this work ( $80 \%$ men, $20 \%$ women) and the small sample size, which needs further investigation on a larger number of patients. Future studies should also target the relation between S100B and estrogen receptors.

No available studies regarding the link between serum or skin S100B and gender were published. However, some studies reported relation between gender and cerebrospinal fluid (CSF) S100B. Vicente et al., in 2007, suggested astrocytes as putative targets for estrogen as an explanation of their finding of higher S100B CSF levels in women than in men. ${ }^{19}$ Conversely, other studies found that either the concentration of S100 in CSF did not differ substantially with gender or were substantially higher in men than in women. ${ }^{20.21}$

There are some possible mechanisms that may support psoriasis/S100B relation. It is already well studied the role of specific skin cells such as monocytes/macrophages, lymphocytes and neutrophils, as well as their related cytokines, e.g. TNF- $\alpha$, in the pathogenesis of psoriasis. 3,13,22,23 Interestingly, S100B was also reported to enhance neutrophil sensitivity to specific chemoattractant molecules. ${ }^{24}$ Furthermore, serum S100B might be required for inducing inflammatory 
gene expression in circulating monocytes. ${ }^{25}$ It may also engage receptor for advanced glycation end products (RAGE) in macrophages thereby stimulating a local inflammatory response and release of TNF- $\alpha$; an important cytokine that is upregulated in psoriasis. ${ }^{22,26}$

Several reports about stress as an important cross point between psoriasis and S100B are available. ${ }^{14,27}$ On one hand, the role of stress as an important precipitating factor in the pathogenesis of psoriasis is well studied. ${ }^{27,28}$ On the other hand, stress was also reported to increase serum levels of S100B in rats. S100B is reported to have neurotrophic and neuroprotective properties and its release during stress could be attributed to a physiological role in the CNS. ${ }^{14}$ The effect of stress on S100B may be mediated through a stress-induced increase in adrenocorticotropic hormone (ACTH) levels or alteration of in-vivo extracellular levels of 5-hydroxytryptamine (5-HT) in brain tissue. ${ }^{29-31}$ Stress may also increase the permeability of the blood-brain barrier for S100B through activation of brain mast cells. ${ }^{32}$ Further research on the relation between S100B in psoriatic patients with different grades of disease-associated stress seems mandatory.

The present study of S100B skin expression within control group was consistent with known reports in which S100B protein is expressed in epidermal Langerhans' cells and melanocytes, while in the dermis it is expressed in Schwann cells, sensory corpuscles, terminal secretory segment of the eccrine sweat gland and in the inner zone of the hair follicle. ${ }^{8}$ Its immunoreactivity is found in the cytoplasm. ${ }^{12}$ Such consistent findings within control group supported the reliability of findings within the cases in the present study.

The significantly higher serum level in relation to higher than lower grades of S100B protein expression in lesional skin might be attributed to increased vascularity in lesional psoriatic skin allowing higher amounts of the protein to reach the lesional skin proportionate to the higher serum level. Conversely, in non-lesional skin, the relation between serum level and grade of skin expression of S100B was not significant, which could be explained by the normal vascularity in this area. On the other hand, the absence of a statistically significant correlation between the mean S100B serum level and S100B skin expression grade in lesional and non lesional skin biopsies was quite unexpected, but it might be ascribed to the small sample size in our study.

\section{CONCLUSION}

In conclusion, the present study points to a potential link between psoriasis and S100B protein with higher serum and skin expression in patients than in controls. Such a link may help to further explore the complex pathogenesis of psoriasis.

\section{REFERENCES}

1. Raut AS, Prabhu RH, Patravale VB. Psoriasis clinical implications and treatment: a review. Crit Rev Ther Drug Carrier Syst. 2013;30:183-216.

2. Weigle N, McBane S. Psoriasis. Am Fam Physician. 2013;87:626-33.

3. Ghoreschi K, Weigert C, Röcken M. Immunopathogenesis and role of T cells in psoriasis. Clin Dermatol. 2007;25:574-80.

4. Hattinger E, Zwicker S, Ruzicka T, Yuspa SH, Wolf R. Opposing functions of psoriasin (S100A7) and koebnerisin (S100A15) in epithelial carcinogenesis. Curr Opin Pharmacol. 2013;13:588-94.

5. Santamaria-Kisiel L, Rintala-Dempsey AC, Shaw GS. Calcium-dependent and -independent interactions of the S100 protein family. Biochem J. 2006;396:201-14.

6. Donato $\mathrm{R}$. Functional roles of $\mathrm{S} 100$ proteins, calcium-binding proteins of the $\mathrm{EF}$ hand type. Biochim Biophys Acta. 1999;1450:191-231.

7. Eckert RL, Broome AM, Ruse M, Robinson N, Ryan D, Lee K. S100 proteins in the epidermis. J Invest Dermatol. 2004;123:23-33.

8. Böni R, Burg G, Doguoglu A, Il EC, Schäfer BW, Müller B, et al. Immunohistochemical localization of the $\mathrm{Ca} 2+$ binding $\mathrm{S} 100$ proteins in normal human skin and melanocytic lesions. Br J Dermatol. 1997;137:39-43.

9. Undén J, Christensson B, Bellner J, Alling C, Romner B. Serum S100B levels in patients with cerebral and extracerebral infectious disease. Scand J Infect Dis. 2004;36:10-3.

10. Paradisi A, Guidi B, Diociaiuti A, Forni F, Scribano D, Sisto T, et al. Increased S100B protein serum levels in psoriasis. J Dermatol Sci. 2007;48:148-50.

11. Fredriksson T, Pettersson U. Severe psoriasis-oral therapy with a new retinoid. Dermatologica. 1978;157:238-44.
12. Park HR, Min SK. Expression of S100A2 and S100B proteins in epithelial tumors of the skin. J Cutan Pathol. 2003;30:373-8.

13. Donato R, Sorci G, Riuzzi F, Arcuri C, Bianchi R, Brozzi F, et al. S100B's double life: intracellular regulator and extracellular signal. Biochim Biophys Acta. 2009;1793:1008-22.

14. Scaccianoce S, Del Bianco P, Pannitteri G, Passarelli F. Relationship between stress and circulating levels of S100B protein. Brain Res. 2004;1004:208-11.

15. Heizmann CW. S100B Protein in Clinical Diagnostics: Assay Specificity. Clin Chem. 2004;50:249-51.

16. Glitzner E, Korosec A, Brunner PM, Drobits B, Amberg N, Schonthaler HB, et al. Specific roles for dendritic cell subsets during initiation and progression of psoriasis. EMBO Mol Med. 2014;6:1312-27.

17. Cumberbatch M, Singh M, Dearman RJ, Young HS, Kimber I, Griffiths CE. Impaired Langerhans cell migration in psoriasis. J Exp Med. 2006;203:953-60.

18. Sakatani S, Seto-Ohshima A, Shinohara Y, Yamamoto $Y$, Yamamoto H, Itohara $S$, et al. Neural-activity-dependent release of S100B from astrocytes enhances kainate-induced gamma oscillations in vivo. J Neurosci. 2008;28:10928-36.

19. Vicente E, Tramontina F, Leite MC, Nardin P, Silva M, Karkow AR, et al. S100B levels in the cerebrospinal fluid of rats are sex and anaesthetic dependent. Clin Exp Pharmacol Physiol. 2007;34:1126-30.

20. van Engelen BG, Lamers KJ, Gabreels FJ, Wevers RA, van Geel WJ, Borm GF. Age-related changes of neuron-specific enolase, S-100 protein, and myelin basic protein concentrations in cerebrospinal fluid. Clin Chem. 1992;38:813-6. 
21. Nygaard O, Langbakk B, Romner B. Age- and sex-related changes of S-100 protein concentrations in cerebrospinal fluid and serum in patients with no previous history of neurological disorder. Clin Chem. 1997;43:541-3.

22. Krueger JG. The immunologic basis for the treatment of psoriasis with new biologic agents. J Am Acad Dermatol. 2002;46:1-23; quiz 23-6.

23. Mehlis S, Gordon KB. From laboratory to clinic: rationale for biologic therapy. Dermatol Clin. 2004;22:371-7, vii-viii.

24. Omori K, Ohira T, Uchida Y, Ayilavarapu S, Batista EL Jr, Yagi M, et al. Priming of neutrophil oxidative burst in diabetes requires preassembly of the NADPH oxidase. J Leukoc Biol. 2008;84:292-301.

25. Donato R. RAGE: a single receptor for several ligands and different cellular responses. The case of certain S100 proteins. Curr Mol Med. 2007;7:711-24.

26. Saini A, Al-Shanti N, Stewart CE. Waste management-cytokines, growth factors and cachexia. Cytokine Growth Factor Rev. 2006;17:475-86.

27. Griffiths CEM, Camp RDR, Barker JNWN. Psoriasis. In: Burns T, Breathnach S, Cox N, Griffiths C, editors. Rook's Textbook of Dermatology. Seventh Edition, Blackwell Science, 2008; pp: 1731-1800.

28. Mazzetti M, Mozzetta A, Soavi GC, Andreoli E, Foglio Bonda PG, Puddu P, et al. Psoriasis, stress and psychiatry: psychodynamic characteristics of stressors. Acta Derm Venereol Suppl (Stockh). 1994;186:62-4.

29. Suzuki F, Kato K, Kato T, Ogasawara N. S-100 protein in clonal astroglioma cells is released by adrenocorticotropic hormone and corticotropin-like intermediate-lobe peptide. J Neurochem. 1987;49:1557-63.

30. Whitaker-Azmitia PM, Murphy R, Azmitia EC. Stimulation of astroglial 5-HT1A receptors releases the serotonergic growth factor, protein S-100, and alters astroglial morphology, Brain Res. 1990;528:155-8.

31. Carrasco GA, Van de Kar LD. Neuroendocrine pharmacology of stress. Eur J Pharmacol. 2003;463:235-72.

32. Kandere-Grzybowska K, Gheorghe D, Priller J, Esposito P, Huang M, Gerard N, et al. Stress-induced dura vascular permeability does not develop in mast celldeficient and neurokinin- 1 receptor knockout mice. Brain Res. 2003;980:213-20.
MAILING ADDRESS:

Samar Abdallah M. Salem

Dermatology \& Venereology Department

Faculty of Medicine

Ain Shams University,

Abbasseya Square, Cairo, Egypt.

E-mail:smousasalem@yahoo.com

How to cite this article: Salem SAM, El-Khateeb EA, Harvy M, Emam HME, Abdelaal W, El Nemr R, El-Hagry OO. Study of serum levels and skin expression of S100B protein in psoriasis. An Bras Dermatol. 2017;92(3):323-8. 